\title{
Application of Peer Psychological Counseling in Psychological Crisis Intervention of Primary and Middle School Bullying
}

\author{
Zhao Kang \\ School of Education \\ Research Center for Mental Health Education \\ China West Normal University \\ Nanchong, China 637009
}

\author{
Mengqi Sun \\ School of Education \\ Research Center for Mental Health Education \\ China West Normal University \\ Nanchong, China 637009
}

\author{
Shangming Wang \\ Nanchong Senior High School of Sichuan Province \\ Nanchong, China 637000
}

\begin{abstract}
In recent years, because the psychological crisis caused by school bullying hasn't been solved in time, many events that primary and middle school students go to extremes emerge. This problem has become a hot topic to people from all walks of life. Peer psychological counseling has the characteristics of less impedance, wide coverage and rapid effect. It can effectively cope with the psychological crisis caused by primary and middle school bullying, so it can be used as an important form of psychological intervention in school bullying. In practice, it is necessary to actively improve the peer mutual aid network system, create a good peer mutual help psychological environment and pay attention to relevant skills training and practice supervision to comprehensively improve the overall effect of peer psychological counseling on psychological crisis intervention of school bullying.
\end{abstract}

Keywords-peer counseling; school bullying; crisis intervention

\section{INTRODUCTION}

In recent years, with the deepening of the comprehensive social governance work, the education management departments and primary and middle schools have increased the intensity of school comprehensive management, which greatly reduces the probability of primary and middle school bullying. Due to the large number of primary and middle school students in China, the wide distribution and very obvious regional differences, the bullying phenomenon in primary and middle schools has not been completely eliminated. The incident that psychological crisis caused by school bullying goes to extreme for untimely intervention has emerged constantly. To explore effective psychological crisis intervention and coping strategies has become a hot topic to people from all walks of life. In practice, it is necessary to fully combine the characteristics of primary and middle school students' physical and mental development, scientifically utilize many advantages of peer psychological counseling, improve peer psychological mutual aid network system in primary and middle schools, and comprehensively improve the overall effect from the scientific intervention of peer psychological counseling on psychological crisis caused by school bullying.

\section{The MEANING AND CHARACTERISTICS OF PEER PSYCHOLOGICAL COUNSELING}

\section{A. The Meaning Interpretation of Peer Psychological Counseling}

It should be said that for the psychological counseling work in primary and middle schools, peer psychological counseling is a relatively influential, new and nonprofessional psychological counseling model. As the name implies, "peer" means "friend" and "fellow". Most of the peer groups have the characteristics of basically same age, basically same lifestyle and basically similar values. Therefore, peer psychological counseling refers to the counseling style of psychological aid provided by "friend" or "fellow" who has had contacts and is worth trust in daily life and learning in the process of individual development and growth, especially when encountering various pressures and confusions in daily life. Due to it is a common way for individuals to confide or ask for help when in trouble, peer psychological counseling can be understood as psychological aid activities such as comfort and encouragement, persuasion and support in the process of mutual interaction between their peers with basically same ages.

In fact, in academia there are different understandings of the concept of peer psychological counseling, which leads to different expressions of peer psychological counseling 
course, the peer psychological counsellors are also the best assistants to follow-up services for students in the psychological intervention activities, which can make psychological intervention work in school more active and efficient.

2) Wide coverage and application range of peer psychological counseling: Most peer psychological counselors are class mental members. They have a common living space with the help-seeking students, which facilitate the interaction, communication and coordination between them. It is also convenient for them to provide psychological aid such as comfort, encouragement, persuasion and support. To a certain extent, it can broaden the coverage of psychological aid and crisis intervention for relevant students. At the same time, the full-time psychological counseling teachers in school can obtain more comprehensive information from peer psychological counselors to scientifically grasp the dynamic characteristics of students' psychological development. It is precisely because peer psychological counseling is not much influenced by time and territory that it has greater flexibility and can provide possible psychological aid to help-seeking students on a larger scale. Peer psychological counselors can make use of their own advantages to find out the students with various signs of psychological crisis in time and actively help them deal with various psychological problems, which naturally contributes to the development of students' good social adaptability.

psychological counseling has positive practical value and has been continuously promoted and applied in the current mental health education activities carried out by schools.

\section{B. Analysis of the Main Characteristics of Peer Psychological Counseling}

1) Relatively low resistance and timely effect of peer psychological counseling: In current psychological counseling practice of primary and middle schools, we can often see such a phenomenon: due to the age difference and identity of teachers and students, primary and middle school students may often have strong resistance to school psychological counseling teachers. When encountering psychological problems or confusions, they rarely ask for help from relatively professional school psychological counselors, but prefer peer psychological counselors in student group. This is because the peer psychological counselors have similar ages and values with and the helpseeking students. At the same time, they have extremely similar life layers, basically familiar with and understand each other's psychological dynamics. Peer relationships make students with psychological confusions are more willing to open their hearts to talk with them so that they can detect the signs of psychological crisis on students and deal with them in time. For the problems that peer psychological counsellors can't easily solve, it is also helpful for them to provide more professional counseling and intervention in time by transferring relevant information to full-time psychological counseling teachers in school. Of
III. THE ADVANTAges OF PEERS PSYCHOLOGICAL COUNSELING IN PSYCHOLOGICAL CRISIS INTERVENTION OF PRIMARY AND MIDDLE SCHOOL BULLYING

In recent years, many researchers and practitioners of mental health education in China have paid special attention to educational mode of peer psychological counseling in the process of primary and middle school bullying, and constantly try to fully integrate them into school psychological crisis intervention system. The role of peer psychological counseling in psychological crisis intervention of primary and middle schools has been constantly presented.

\section{A. To Constantly Enrich and Improve Psychological Crisis Intervention System of Primary and Middle School Bullying and Comprehensively Reduce the Occurrence Probability of Primary and Middle School Bullying}

The primary and middle school bullying seems to happen suddenly. In fact, there is a gradual process from quantitative change to qualitative change. If primary and middle school students are always living in a harmonious, quiet and cheerful campus environment, then students' subconscious will not associate school's good learning and life scene with school bullying. By establishing a comprehensive and systematic peer psychological crisis intervention system, it is possible to timely find and identify potential unstable factors in primary and middle schools and take effective measures in time to avoid problems or escalation of conflicts which will induce school bullying. With the help of education campaign 
personally held by peer psychological counselors, primary and middle school students can not only fully feel the true sense of peer psychological counseling but also truly experience the sense of achievement brought by peer psychological counseling, which will bring positive effects on comprehensive popularization of mental health knowledge and ideas and the improvement of students' psychological literacy level. At the same time, peer psychological counsellors have more opportunities to fully integrate into the daily life of primary and middle school students and understand the characteristics and intensity of various psychological crises. They can help primary and middle school students construct a scientific and rational cognitive system and learn to treat various problems scientifically and rationally in order to comprehensively improve psychological literacy level of primary and secondary school students.

\section{B. To Grasp the Psychological Development of Primary and Middle School Students in Time and Start Primary and Middle School Psychological Crisis Intervention System Can Greatly Reduce the Negative Influence of School Bullying}

Although peer psychological counseling is not completely comparable to the school's full-time teachers in terms of its function, it is an important way to effectively help primary and middle school students get rid of the psychological distress caused by school bullying, and an important source to get external psychological support. When primary and middle school students encounter various psychological pressures or confusions in the event of school bullying, the first object that they will think of seeking help is the peer psychological counsellors around them. Peer psychological counselors can timely appease and guide students involved in psychological crisis caused by school bullying and take active measures to provide psychological aid, so that students involved in school bullying crisis can make scientific and effective responses. With the scientific, standardized and meticulous psychological crisis intervention work of peer psychological counselors and tutors to actively guide the panic and abnormal behaviors of the students involved, we can effectively control the vicious development of school bullying and win more time and space for the complete solution of school bullying, which will inevitably reduce the negative impact of school bullying.

\section{With Peer Psychological Counseling Which Intervenes} in the Psychological Crisis of Primary and Middle School Students Timely and Effectively, Effectively Improving the Resilience of Primary and Middle School Bullying and Comprehensively Extending the Effect of Psychological Crisis Intervention

Part of primary and middle school students may not be able to cope with school bullying, which may lead to a more serious psychological crisis even affect their lifelong development. To fully eliminate the serious psychological distress caused by school bullying to primary and middle school students, it is far from enough to only rely on several psychological counseling education courses offered by school and the twice or three times psychological counseling of teachers. Peer psychological counselors are psychological counselors generated among student groups. Most of them have strong professional knowledge, good personality characteristics, correct outlook on life and values. Living in student groups, they are very easy to feel the psychological and behavioral changes of students around them. With their efforts and help, primary and middle school students can learn to correctly understand and scientifically respond to school bullying and restore their psychological balance as soon as possible. Through their own positive comfort and persuasion, peer psychological counselors can help students involved in school bullying crisis quickly resume their thinking and judgment, and adjust their negative emotions and over-excited ideas in time. At the same time, the influence of peer psychological counseling may extend to all aspects of primary and middle school students' daily life and learning. With the guidance and help of school full-time psychological counseling teachers, peer psychological counsellors can carry out psychological crisis intervention work systematically, which can not only effectively share the heavy work of school full-time psychological counseling teachers, but also enable the psychological crisis intervention work to be carried out in the natural situation. While reducing the negative impact of school bullying on students and schools, it can also effectively improve the ability of helping others and comprehensively improve their psychological literacy.

\section{The ApPlication PATH OF PEER PSYCHOLOGICAL COUNSELING IN PSYCHOLOGICAL CRISIS INTERVENTION OF PRIMARY AND MIDDLE SCHOOL BULLYING}

It is precisely because the effective intervention of psychological crisis caused by primary and middle school bullying can help the students involved reduce their psychological pressure and help them to restore their psychological balance quickly, actively exploring scientific intervention strategies in educational practice has become the realistic appeal of times development. The intervention mechanism of psychological crisis in primary and middle school bullying includes the early warning mechanism before school bullying crisis happens, the handling mechanism when bullying crisis is happening and the aftermath mechanism after it happens. These corresponding mechanisms play an important role in dealing with primary and middle school bullying and the recovery of the involved students' psychological trauma.

\section{A. A Perfect Peer Mutual Aid Network System Can Effectively Intervene in Psychological Crisis Caused by Primary and Middle School Bullying}

Primary and middle schools should gradually improve the peer psychological mutual aid network system, which is an important force for psychological crisis intervention in school bullying. Schools may set up mental health education centers or specialized associations to carry out specific work. Each class may set up mental member as needed. It should be said that the class mental member is an important force in carrying out peer psychological counseling work. This is 
ways, a good campus culture atmosphere can be created. At the same time, with the rapid development of network technology, current primary and middle schools can make full use of online psychological counseling, online chat rooms and online psychological salons to carry out a variety of activities aiming to intervene in psychological crisis caused by school bullying, which can not only fully mobilize the students' initiative in learning mental health knowledge, but also effectively prevent the occurrence of various psychological problems. early prevention, early intervention". By conducting work such as general survey of mental health, psychological crisis troubleshooting, psychological dynamics and health information tracking feedback, schools can pay attention to students' psychological and behavioral changes at any time. Schools should comprehensively analyze and formulate the factors that may induce students' psychological crisis due to school bullying, and intervene in time when finding the indication. Practice has proved that focusing on early prevention can avoid school bullying caused by psychological problems of some students. After primary and middle school bullying, it is necessary to follow up the psychological crisis intervention work in time, promptly resolve the irritability and fear of students, guide them to correctly treat school bullying, and pay attention to deal with the aftermath to better ease the psychological crisis caused by school bullying to primary and middle school students. After the end of school bullying, we should conduct further analysis and research, carefully summarize the incident, clean up the omissions in handling process and take timely measures to remedy. At the same time, the recovery system for school bullying should be established as soon as possible to help primary and middle school students go back to normal study and life as soon as possible.

\section{B. To Strive to Create a Good Peer Mutual Help}

Atmosphere, Comprehensively Prevent and Control

School Bullying and Provide Convenience for

Psychological Crisis Intervention

Schools must find ways to prevent the occurrence of various types of behaviors of school bullying, actively provide various conveniences for peer mutual help and promote the healthy growth of primary and middle school students. Schools should pay attention to letting peer psychological counselors deeply carry out work in class and dormitory and integrate into students' daily life. In practice, they should pay special attention to those students who are more introverted in daily life, create a benign and friendly psychological environment and actively carry out psychological exchanges. Peer psychological counselors can publicize and popularize mental health knowledge in a variety of ways, because many psychological problems of primary and middle school students are often caused by the lack of basic mental health knowledge. When helping students face the problem of school bullying bravely, peer psychologically counselors should make full use of school's various media and public opinion positions such as campus radio, school newspapers or WeChat groups and other communication tools to deliver messages. By academic lectures, psychological knowledge contests, psychological book readings and psychological sitcom shows and other

\section{To Strengthen the Training and Supervision of Peer Psychological Counselors, Help Teachers and Students of the Whole School to Respond to School Bullying Scientifically and Improve Counselors' Ability of Psychological Crisis Intervention}

In order to better carry out school psychological crisis intervention work, peer psychological counselors must have relevant theories and operational techniques for psychological counseling and crisis intervention. So it is particularly important to strengthen the selection, training and education supervision of school psychological counselors. The characteristics of peer psychological counselors are the key factors. It is important to test their knowledge structure, outlook on life and values, and whether they have good qualities such as right self-concept, perfect personality and flexible counseling skills. This is because peer psychological counselors can not only fully help and induce students to vent their bad feelings but also give positive guidance to their study, life and interpersonal relationships. It is true that peer psychological counseling can make up for the lack of school psychological counselors, however, it should be noted that psychological crisis intervention is a highly professional job, and it is necessary to pay attention to give peer psychological counselors systematic professional training and educational supervision, which is the responsibility of school's psychological counseling education work. Schools should strengthen the scientific guidance of peer psychological counselors and strive to create conditions to continuously improve their professional quality, so as to help school teachers and students learn to deal with school bullying and improve their ability to handle various crisis.

\section{CONCLUSION}

It should be said that the practice of psychological counseling education in primary and middle schools fully proves that peer psychological counseling can effectively cope with and interfere in the psychological crisis caused by primary and middle school bullying. We should actively support the in-depth development of peer psychological counseling work in primary and middle schools, comprehensively improve students' mental health level, create a harmonious and quiet campus atmosphere and escort the healthy growth of primary and middle school students. 


\section{ACKNOWLEDGMENT}

This research was financially supported by the Key Topics in Education and Scientific Research of the Education Department of Sichuan Province [(2017)336]: Study on Bullying Behavior and Intervention Strategies in Primary and Secondary Schools. Key Research Base of Sichuan Province Philosophy and Social Sciences-Project of Sichuan Center for Education Development Research: Research on Campus Bullying in Primary and Secondary Schools (CJF17028).

\section{REFERENCES}

[1] Qiu Zhenliang,Qiu Zengzhi. The Application of Peer Counseling in Psychological Crisis Intervention in Primary and Secondary Schools. Mental Health Education in Primary and Secondary School, No.21, pp. 21-23, 2010.

[2] Zhang Liyu."Upperclassman" Peer Psychological Counseling Model Research and Practice. Journal of Heihe University, No.6, pp.100-102, 2016.

[3] Yan Nongqiu. The Theory and Technique of Peer Counseling. Guangzhou: Zhongshan University Press, 2007.

[4] Zhou Hongwu. Construction of School Psychological Crisis Intervention System. Mental Health Education in Primary and Secondary School, No.4, pp. 8-10, 2005.

[5] Zhou Li, Lei Li. American Peer Psychological Consultation Model and Its Enlightenment to China. Theory and Practice of Education,No.15, pp. 51-53, 2016.

[6] Liu Yan. Practical Exploration on the Training of Peer Psychological Counselor in Colleges and Universities.Journal of Zhenjiang College, No.1, pp. 69-72, 2011.

[7] Wu Yingxin. On Peer Psychological Mutual Assistance in Campus Crisis. Ability and Wisdom, No.17, p. 141, 2018.

[8] Sun Binghai,Sun Xinyi. Application of Peer Counseling Model in School Psychological Counseling. Education Review, No.6, pp.49-51, 2003.

[9] Chen Guohai. Peer Help Center for Canadian Universities and Its Enlightenment, Journal of Higher Education Research, No.3, pp.9497, 2006. 